\title{
Oncocytic Biliary Cystadenocarcinoma Is a Form of Intraductal Oncocytic Papillary Neoplasm of the Liver
}

Yoshiko Sudo, M.D., Kenichi Harada, M.D., Koichi Tsuneyama, M.D., Kazuyoshi Katayanagi, M.D., Yo Zen, M.D., Yasuni Nakanuma, M.D.

Department of Pathology, Kanazawa University School of Medicine, Kanazawa, Japan

Biliary cystadenocarcinoma with oncocytic differentiation was first reported in 1992. This is a report of a second case. The patient (a 71-year-old man) was admitted to our hospital complaining of abdominal fullness. Multicystic lesions were identified in the left hepatic lobe radiologically. The patient died of peritoneal dissemination of carcinoma 20 months later. At autopsy, the tumor of the left hepatic lobe was found to be composed of adjoining multiple cystic lesions and a solid lesion with infiltration of the hepatic hilus and peritoneal dissemination. Histologically, the multicystic lesions were covered by papillary neoplastic epithelial cells with an eosinophilic granular cytoplasm resembling that of oncocytes and a fine fibrovascular core. The cyst wall was fibrous, but there was no mesenchymal stroma. In the solid lesion and infiltrated areas, acidophilic and granular carcinoma cells formed small glandular or solid cord patterns with much mucin secretion (mucinous carcinoma). Immunohistochemically, carcinoma cells of both components were found to contain many mitochondria and showed the phenotypes of hepatocytes and cholangiocytes. Interestingly, the intrahepatic biliary tree also was invaded by carcinoma cells. This may be a case of intraductal oncocytic papillary neoplasm of the left hepatic lobe followed by secondary cystic dilatation of the affected bile duct.

KEY WORDS: Biliary cystadenocarcinoma, Intraductal oncocytic papillary neoplasm, Mesenchymal stroma, Oncocyte.

Mod Pathol 2001;14(12):1304-1309

Copyright $\odot 2001$ by The United States and Canadian Academy of Pathology, Inc.

VOL. 14, NO. 12, P. 1304, 2001 Printed in the U.S.A.

Date of acceptance: July 12, 2001.

Address reprint requests to: Yasuni Nakanuma, M.D., Department of Pathology (II), Kanazawa University School of Medicine, Kanazawa 920-8640, Japan; e-mail: pbcpsc@kenroku.kanazawa-u.ac.jp; fax: 81-76-234-4229.
Biliary cystadenocarcinoma is usually of a mucinous type. In females, this tumor is frequently associated with mesenchymal stroma wall and shows a rather benign clinical course $(1,2)$. Histologically, foci of biliary cystadenoma often are admixed with carcinoma components. However, the clinicopathologic features and histogenesis of biliary cystadenocarcinoma in males and/or without mesenchymal stroma remain unexplored.

Recently, Wolf et al. (3) reported "oncocytic differentiation of intrahepatic biliary cystadenocarcinoma." Their patient was a 56 -year-old man, and most of the tumor cells were found to contain abundant granular eosinophilic cytoplasm by light microscopy and a large number of densely packed mitochondria by electron microscopy. Their patient died of peritoneal dissemination 25 months after surgical resection. This case lacked a mesenchymal stroma wall.

We recently have encountered a similar case of intrahepatic biliary cystadenocarcinoma with oncocytic changes and peritoneal dissemination at the terminal stage. In this case, the intrahepatic bile ducts also were involved. Herein, this case is reported with an emphasis on histopathologic findings and the histogenesis.

\section{CASE REPORT}

A 71-year-old man complaining of abdominal fullness and chest pain was admitted at Kanazawa University Hospital, Kanazawa, Japan, in July 1998. Computed tomography and magnetic resonance imaging revealed multiple cystic lesions and an adjacent solid lesion in the left hepatic lobe, as well as carcinomatous dissemination (Fig. 1). He was clinically diagnosed as having biliary cystadenocarcinoma with abdominal dissemination.

Laboratory data of hepatic function at admission (Table 1) were almost normal except for elevation of $\gamma$ GTP $(1.53 \mathrm{IU} / \mathrm{L})$ and CRP $(18.0 \mathrm{mg} / \mathrm{dL})$. Peripheral leukocytes were increased $(12,000 / \mathrm{mL})$. His abdominal fullness worsened and, in January 2000, massive ascites developed. He was given chemo- 


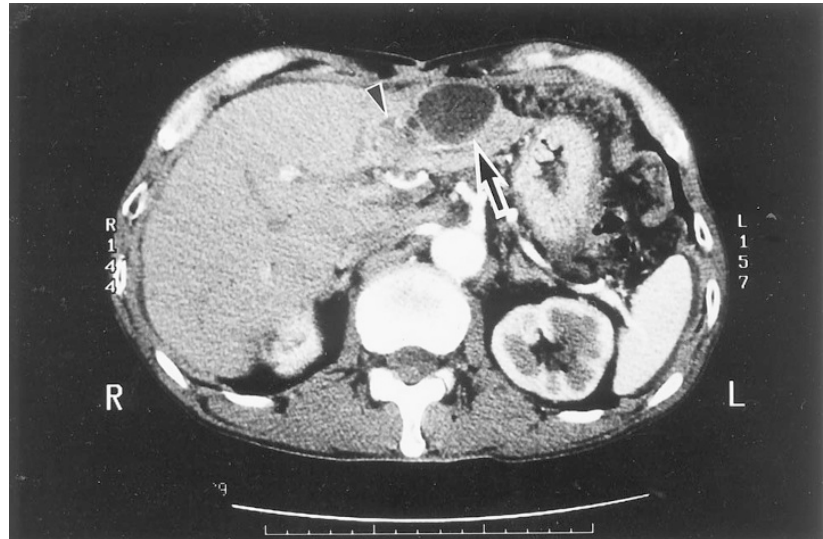

FIGURE 1. Computed tomography shows multiple cystic lesions $($ arrow). Solid lesion (arrow head) is seen in the hepatic lobe .

therapy injections of Picibanil (10KE) and CDDP (cis-diammine dichloroplatinum, $50 \mathrm{mg}$ each) into the abdominal cavity two times; however, his condition deteriorated. Total serum bilirubin elevated to $21.1 \mathrm{mg} / \mathrm{dL}$, and the other laboratory data were as follows: GOT, 187 IU/L; GPT, 163 IU/L; ALP, 2609 $\mathrm{IU} / \mathrm{L}$. He died on March 1, 2000. An autopsy was performed 14 hours after his death.

\section{Pathologic Findings at Autopsy}

The left lateral segment of the liver (1320 g) was atrophic and was replaced by multiple cystic lesions and the adjoining solid lesion (Fig. 2, A-B). The largest cystic lesion was $4 \mathrm{~cm}$ in diameter. Other small cystic lesions were adjacent to this large cyst. The cysts contained mucinous fluid. The internal surface of the cysts was rather smooth but multifocally granular and partly papillary configurations. The solid lesion next to the cystic lesion was yellow-green and mucinous on the cut surface. The border of this solid lesion was relatively clear. Between the cystic and solid lesions, fibrous tissue was present. Carcinomatous infiltration was seen in the hepatic hilus and hepatoduodenal ligament. The intrahepatic bile duct of the right lobe was variably dilated, and cholestasis was evident. There
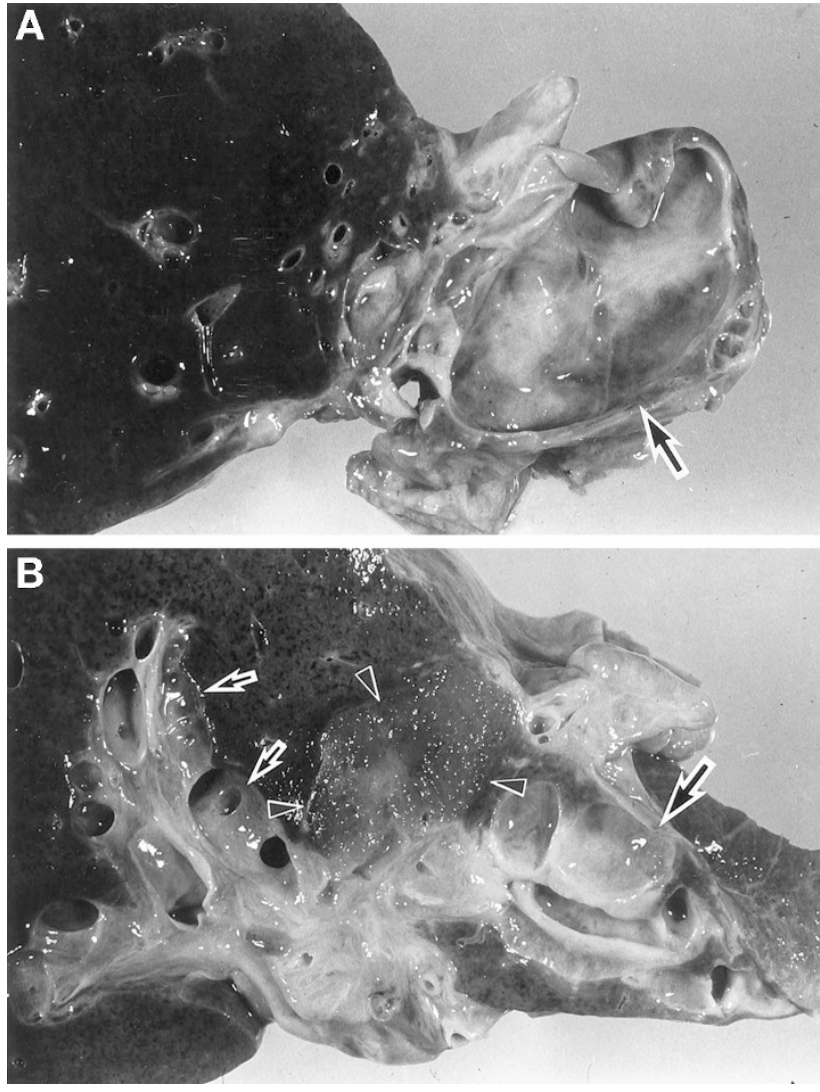

FIGURE 2. A, B, Left hepatic lobe (lateral segment) is replaced by multiple cystic lesions (large arrows) and a solid lesion (arrow heads). The largest cyst is $4 \mathrm{~cm}$ in diameter. The other cystic lesions are adjacent to this large cyst. The cysts are mucinous. Intrahepatic biliary tree of the right lobe also shows significant dilatation (small arrows). A and $\mathbf{B}$ show different levels of autopsied liver.

was no direct communication between the multicystic lesions and dilated intrahepatic bile duct.

Histologically, the cyst wall was composed of rather dense fibrous tissue, and no mesenchymal stroma was recognizable. Partly, there was marked papillary proliferation of the lining epithelial cells, showing eosinophilic cytoplasm with edematous and myxoid fibrovascular cores (Fig. 3, A-B). The remaining epithelial cells of the cyst wall were multilayered cuboidal to low columnar with a pseudo-

TABLE 1. Laboratory Data at Admission

\begin{tabular}{|c|c|c|c|c|c|}
\hline GOT & 21 & $\mathrm{IU} / \mathrm{L}$ & WBC & 12000 & $/ \mathrm{mL} \uparrow$ \\
\hline GPT & 12 & $\mathrm{IU} / \mathrm{L}$ & $\mathrm{RBC}$ & 386 & $\times 10^{4} / \mathrm{mL}$ \\
\hline ALP & 271 & $\mathrm{IU} / \mathrm{L}$ & $\mathrm{Hb}$ & 13.5 & $\mathrm{~g} / \mathrm{dL}$ \\
\hline LDH & 264 & $\mathrm{IU} / \mathrm{L}$ & Plts & 12.5 & $\times 10^{4} / \mathrm{mL}$ \\
\hline LAP & 54 & $\mathrm{IU} / \mathrm{L}$ & CRP & 18.0 & $\mathrm{mg} / \mathrm{dL} \uparrow$ \\
\hline $\mathrm{ChE}$ & 3.6 & $\mathrm{IU} / \mathrm{mL}$ & & & \\
\hline T-Bil & 0.6 & $\mathrm{mg} / \mathrm{dL}$ & HBsAg & $(-)$ & \\
\hline$\gamma$ GTP & 153 & $\mathrm{IU} / \mathrm{mL} \uparrow$ & HCVAb & $(-)$ & \\
\hline BUN & 18 & $\mathrm{mg} / \mathrm{dL}$ & & & \\
\hline $\mathrm{Cr}$ & 1.0 & $\mathrm{mg} / \mathrm{dL}$ & CEA & 4.4 & $\mathrm{ng} / \mathrm{mL}$ \\
\hline $\mathrm{Na}$ & 141 & $\mathrm{mEq} / \mathrm{L}$ & CA19-9 & 37 & $\mathrm{U} / \mathrm{mL}$ \\
\hline $\mathrm{K}$ & 4.1 & $\mathrm{mEq} / \mathrm{L}$ & AFP & 2.4 & $\mathrm{ng} / \mathrm{mL}$ \\
\hline $\mathrm{Cl}$ & 103 & $\mathrm{mEq} / \mathrm{L}$ & PIVKA-II & 17 & $\mathrm{AU} / \mathrm{mL}$ \\
\hline
\end{tabular}

Laboratory data of hepatic function at admission were almost normal except for an elevation of $\gamma$ GTP (153IU/L). WBC and CRP were also elevated. 
papillary pattern. The lining epithelia showed atypical nuclei with nucleoli and an eosinophilic granular cytoplasm (Fig. 3C). The cytoplasm of these papillary carcinomas contained fine droplets positive for alcian blue $\mathrm{pH} 2.5$ and mucicarmine stainings. The luminal surface was also linearly positive for these mucinous stainings.

In solid areas, tumor cells were floating in a mucinous substance or fibrous tissue and formed small glands, acini, or small solid nests (mucinous carcinoma) (Fig. 3, C-D). Tumorous lesions in the peritoneum showed a mucinous pattern. In these areas, the cytoplasm of the tumor cells was distinctly eosinophilic and granular. Cellular features of the epithelia lining the cysts and of the mucinous area resembled each other. These two components of the cystic lesion and solid lesion were partly continuous. Taken together, this solid
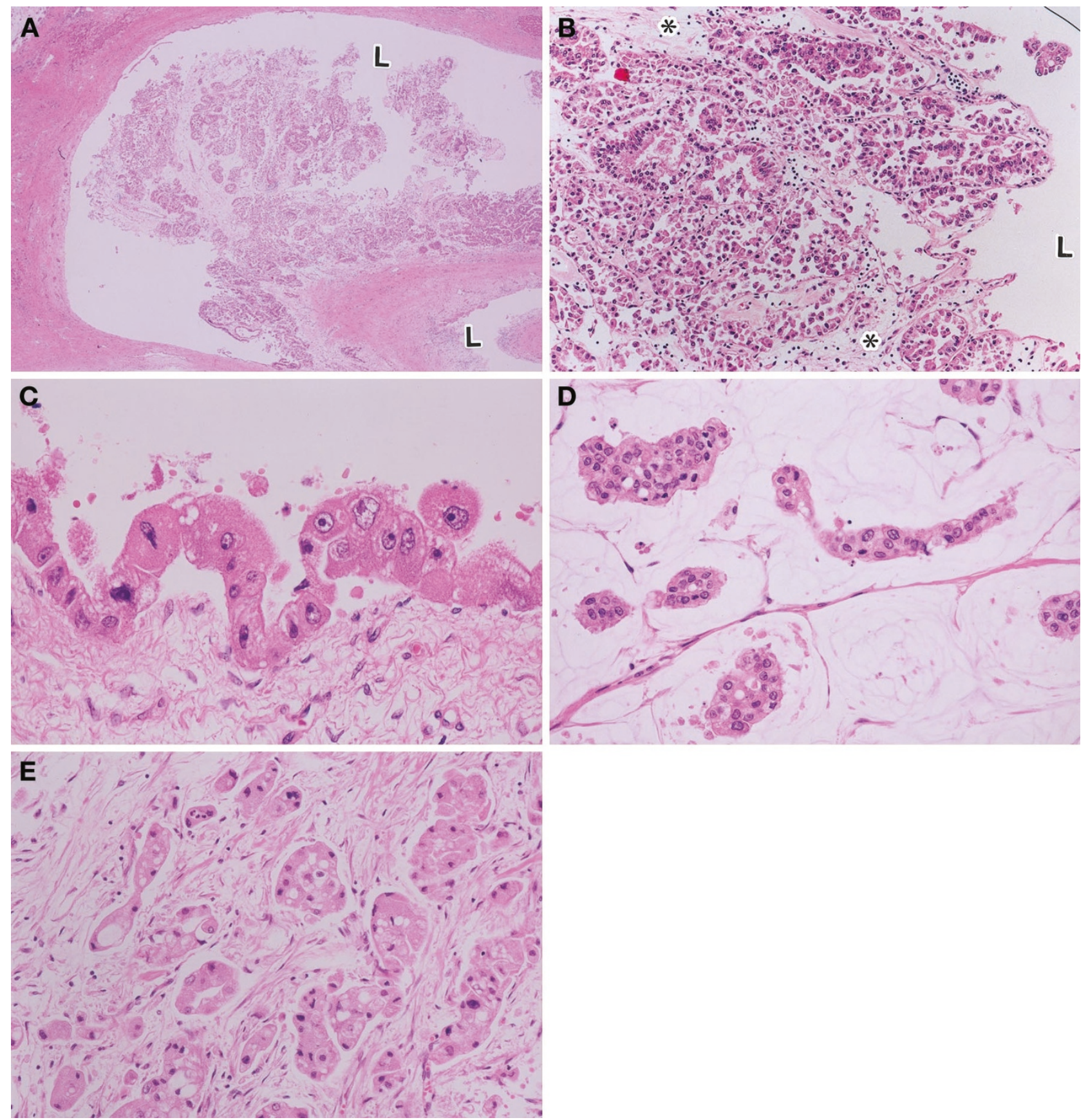

FIGURE 3. A, Histologically, the cyst wall is composed of dense fibrous tissue, while no mesenchymal stroma is recognizable. There is marked papillary neoplastic proliferation (arrows) of the lining epithelia with fibrovascular cores in the cystic lesion. L, lumen of cystic space. HE, $\times 40$. B, The papillary structure of this tumor is evident. The neoplastic epithelia with acidophilic cytoplasm cover the papillae, and the stroma of these papillae are edematous and myxoid $(*)$. The neoplastic epithelia are artificially desquamated. L, bile duct lumen. HE, $\times 150$. C, The cystic walls are lined by multilayered cuboidal to low columnar epithelial cells. The epithelial cells show atypical nuclei with nucleoli and an eosinophilic granular cytoplasm. HE, $\times 400$. D, E, In solid areas, tumor cells with an acidophilic granular cytoplasm are floating in a mucinous substance (D), or embedded in loose fibrous tissue (E). They form small glands, acini, or small solid nests. D, HE, $\times 200$; E, HE, $\times 200$ 
TABLE 2. Primary Antibodies Used in This Case and the Immunohistochemical Results

\begin{tabular}{|c|c|c|c|c|}
\hline Antibody & Source & Dilution & Cystic Area & Solid Area \\
\hline CK7 & DAKO (Glostrup, Denmark) & $1: 50$ & ++ & + \\
\hline CK8 & DAKO & $1: 50$ & + & + \\
\hline CK18 & DAKO & $1: 20$ & + & + \\
\hline CK19 & DAKO & $1: 100$ & + & + \\
\hline CK20 & DAKO & $1: 50$ & - & - \\
\hline Anti-mitochondria antibody & Bio Genex (San Ramon, CA) & $1: 100$ & + & + \\
\hline HepPar-1 & DAKO & $1: 100$ & + & + \\
\hline AFP & DAKO & $1: 600$ & - & - \\
\hline CEA & DAKO & $1: 100$ & - & - \\
\hline CA19-9 & CIS Bio International (Cedex, France) & $1: 10$ & - & - \\
\hline
\end{tabular}

CK, cytokeratin; AFP, $\alpha$-fetoprotein; CEA, carcinoembryonic antigen; CA19-9, carbohydrate antigen 19-9; $(-)$, negative; $(+)$, partially positive; $(+++)$, positive.

area was regarded as being invaded by papillary carcinoma.

The intrahepatic bile duct, particularly in the left lobe, showed an intraductal spread of carcinoma cells resembling those of the cysts in shape and cytologic features.

Immunohistochemical staining using the EnVision system (DAKO, Glostrup, Denmark) and primary antibodies and the results of immunohistochemistry are shown in Table 2 . The cytokeratin (CK) pattern of this tumor was a biliary type (positive for CK7, 8, 18, 19). But CK8 and 19 stainings were weak compared with those in normal biliary epithelia. Carcinoma cells were also clearly positive for HepPar-1 (DAKO) and anti-mitochondrial antibody (Bio Genex, San Ramon, CA), showing granular staining patterns. For HepPar-1 staining, the intensity in positive carcinoma cells was comparable with that in non-neoplastic hepatocytes. Staining with anti-mitochondrial antibody revealed the carcinoma cells to be granular in appearance, implying the presence of many mitochondria in their cytoplasm. Albumin was detected in a majority of tumor cells as in non-neoplastic hepatocytes.

Carcinoembryonic antigen and carbohydrate antigen 19-9 (CA 19-9) gave negative results in all carcinoma components, as did $\alpha$-fetoprotein.

\section{Other Pathologic Findings}

The non-neoplastic liver showed severe cholestasis and portal fibrosis due to carcinomatous obstruction of the intrahepatic large bile duct at the hepatic hilus. In addition, occult cancer was found in the prostate. Histologically, the prostatic carcinoma was a poorly differentiated adenocarcinoma, totally different from the liver tumor.

\section{DISCUSSION}

Biliary cystadenocarcinoma is a rare tumor, comprising only $0.18 \%$ of all the liver tumors registered by the Japanese Liver Cancer Study Group (4). Biliary cystadenoma and a majority of biliary cystade- nocarcinomas are multicystic and are known to be associated with "ovarian-like" mesenchymal stroma $(1,5)$ They occur in women and have a good prognosis after total surgical resection of the tumor. The histogenesis of cystadenocarcinoma with mesenchymal stroma has been discussed, and "ectopic ovary" or "intrahepatic peribiliary gland" may be a precursor (6). Recently, D’Errico et al. (7) reported frequent and marked expression of albumin mRNA and biliary CK in all cases of cystadenoma and cystadenocarcinoma examined, suggesting the tumors arose from pluripotent stem cells.

The histogenesis and clinicopathologic features of biliary cystadenocarcinoma without mesenchymal stroma or arising in men remain unknown. This type of biliary cystadenocarcinoma tends to show a poor prognosis compared with that with mesenchymal stroma. In fact, some authors suggest that these two types differ with respect to histogenesis and biologic behavior in addition to morphology. It seems plausible that intrahepatic biliary cystadenocarcinoma without mesenchymal stroma itself may be heterogenous $(1,8-12)$.

Carcinoma cells of biliary cystadenocarcinoma characteristically showed oncocytic changes in the case presented here. So far, only one case of the intrahepatic biliary cystadenoma with oncocytic differentiation has been reported (3). Both cases showed carcinoma cells with an acidophilic granular cytoplasm resembling oncocytes. Many mitochondria were present in these tumor cells, as detected immunohistochemically in this case and ultrastructurally in Wolf's case (3). The clinical course and terminal features of intraabdominal dissemination were also similar in both cases. In this sense, the two cases can be regarded as representing one category of oncocytic biliary neoplasm.

Recently, Adsay et al. introduced a new disease entity, "intraductal oncocytic papillary neoplasm of the pancreas" (13). This type of tumor develops in middle- to old-aged men as well as women. In this tumor, there is marked cystic dilatation of the pan- 


\begin{tabular}{lll}
\hline & \multicolumn{1}{c}{$\begin{array}{c}\text { Hepatobiliary Mucinous } \\
\text { Cystadenoma }\end{array}$} & $\begin{array}{c}\text { Mucinous Cystic Neoplasm of } \\
\text { the Pancreas }\end{array}$ \\
\hline Multicystic lesions & Always & Always \\
Mucin hypersecretion & Always & Rare or absent \\
Ductal involvement and dilatation & Rare or absent & Always \\
Mesenchymal stromal wall & Always & Good \\
Prognosis after surgical resection & Good & Absent \\
Communication with the main duct & Absent & Frequent in middle-aged women \\
Sex and gender & Frequent in middle-aged women & \\
\hline
\end{tabular}

creatic duct and many mitochondria in the cytoplasm. Grossly, the tumors had mucin-filled cysts containing papillary projections and sometimes dilated ducts communicating with the main cyst lesion. In our case, the papillary neoplasm with oncocytic changes was seen in the wall of multiple cysts as well as intrahepatic bile ducts, suggesting that the cysts are secondarily dilated intrahepatic bile ducts invaded by these carcinoma cells, though direct communication was not demonstrated grossly in our case. Such a scenario also is proposed in intraductal papillary mucinous neoplasm of the pancreas (IPMN).

The distinction between mucinous cystic neoplasm of the pancreas (MCN) and IPMN has been made much clearer recently. That is, a vast majority of cases of IPMN, which is characterized by predominantly intraductal growth of papillary tumor with mucus hypersecretion, is known to develop secondary cystic changes or dilatation of involved ducts appearing as MCN (13). Although this issue with respect to hepatobiliary mucinous cystadenoma and intraductal mucin-producing papillary cholangiocarcinomad (14) has not been studied, there are several similarities between these tumors of the liver and those of the pancreas. The main similarities between hepatobiliary mucinous cystadenoma and MCN, and between intraductal mucin papillary producing cholangiocarcinoma and IPMN, are shown in Tables 3 and 4 . Intraductal oncocytic papillary neoplasm of the pancreas and IPMN share a number of features, including cystogenesis and progression (13), and the presence of an oncocytic papillary neoplasm with mucin-filled multicystic lesions in the liver and pancreas suggests that oncocytic papillary cystadenocarcinoma of the liver (3) is more closely related to intraductal mucin-producing papillary cholangiocarcinoma than to hepatobiliary mucinous cystadenoma.

In this case, there was partial continuation between the papillary carcinoma growing in the intrahepatic bile ductal lumen and invasive solid areas and the latter representing invasive carcinoma. The abundance of extracellular mucin in the invasive areas suggests that the invasive component is a colloid carcinoma. The invasive portion in Wolf's case (3) was also a colloid carcinoma. This is interesting because a substantial proportion of the invasive carcinomas arising in IPMN and also the invasive area of intraductal oncocytic papillary neoplasm of the pancreas (14) are colloid carcinomas. Therefore, the oncocytic biliary cystadenocarcinoma, at least in our case, might have originated from an intraductal oncocytic papillary neoplasm followed by strangulation or obliteration of the affected biliary tree. In this context, "oncocytic biliary cystadenocarcinoma" could be a form of intraductal oncocytic papillary neoplasm of the liver.

Our patient showed the biliary phenotypes CK7 and CK19 and also hepatocellular features and phenotypes (many mitochondria and features such as albumin and HepPar-1) (9). As to the oncocytic changes in non-neoplastic biliary epithelial cells, Tobe et al. (15) reported similar changes in nonneoplastic biliary epithelia. Thus, our case might be one of oncocytic metaplasia of papillary neoplasm of the biliary tree or papillary neoplasm from oncocytic biliary epithelia of the intrahepatic biliary tree.

TABLE 4. Comparison of Intraductal Mucin-Producing Papillary Cholangiocarcinoma and Intraductal Papillary Mucinous Neoplasm of the Pancreas

\begin{tabular}{lll}
\hline & $\begin{array}{c}\text { Intraductal Mucin-Producing } \\
\text { Papillary Cholangiocarcinoma }\end{array}$ & Feoplasm of the Pancreas \\
\hline Ductal involvement and dilatation & Frequent & Frequent \\
Multicystic lesions (secondary) filled with mucin & Frequent & Frequent \\
Mucin hypersecretion & Identifiable sometimes \\
Communication with main duct & Frequently colloid carcinoma & Frequent \\
Advanced form & This case & Frequently colloid carcinoma \\
Oncocytic variant & Male as well as female & Occasional \\
Gender & & Male as well as female \\
\hline
\end{tabular}




\section{REFERENCES}

1. Devaney K, Goodman ZD, Ishak KG. Hepatobiliary cystadenoma and cystadenocarcinoma. A light microscopic and immunohistochemical study of 70 patients. Am J Surg Pathol 1994;18:1078-91.

2. Wheeler DA, Edmondson HA. Cystadenocarcinoma with mesenchymal stroma (CMS) in the liver and bile ducts. A clinicopathologic study of 117 cases, 4 with malignant change. Cancer 1985;56:1434-45.

3. Wolf HK, Garcia JA, Bossen EH. Oncocytic differentiation in intrahepatic biliary cystadenocarcinoma. Mod Pathol 1992; 5:665-8.

4. Japanese Study Group of Primary Liver Cancer. The 14th annual report of primary liver cancer registered in 1996 and 1997. Shinko Pub 2000 (in Japanese).

5. Anthony PP. Tumors and tumor-like lesions of the liver and biliary tract: aetiology, epidemiology and pathology. In: MacSween RNM, Burt AD, Portmann BC, Ishak KG, Scheuen PJ, Anthony PP, editors. Pathology of the liver. 4th ed. London: Churchill Livingstone; 2001. p. 711-75.

6. Terada T, Kitamura Y, Ohta T, Nakanuma Y. Endocrine cells in hepatobiliary cystadenomas and cystadenocarcinomas. Virchows Arch 1997;430:37-40.

7. D'Errico A, Deleonardi G, Fiorentino M, Scoazek JY, Gribioni WF. Diagnostic implications of albumin messenger RNA detection and cytokeratin pattern in benign hepatic lesions and biliary cystadenocarcinoma. Diagn Mol Pathol 1998;76: 289-94.

8. Siren J, Karkkainen P, Luukkonen P, Kiviluoto T, Kivilaakso E. A case report of Biliary cystadenoma and cystadenocarcinoma. Hepatogastroenterology 1998;45:83-9.

9. Tsiftsis D, Christodoulakis M, De Bree E, Sanidas E. Primary intrahepatic biliary cystadenomatous tumors. J Surg Oncol 1997;64:341-6.

10. Asahara T, Itamoto T, Katayama K, Nakahara H, Okamoto Y, Hino $\mathrm{H}$, et al. A case of biliary cystadenocarcinoma of the liver. Hiroshima J Med Sci 1999;48:45-8.

11. Toshimatsu M, Okuda H, Saito A, Obata H, Hanyu F, Nakano M. A case of biliary cystadenocarcinoma with morphologic and histochemical features of hepatocytes. Cancer 1989;64: 1323-8.

12. Iemoto Y, Kondo Y, Fukamati S. Biliary cystadenocarcinoma with peritoneal carcinomatosis. Cancer 1981;48:1664-7.

13. Adsay NV, Adair CF, Heffess CS, Klimstra DS. Intraductal oncocytic papillary neoplasms of the pancreas. Am J Surg Pathol 1996;20:980-94.

14. Chen MF, Jan YY, Chen TC. Clinical studies of mucinproducing cholangiocellular carcinoma: a study of 22 histopathology-proven cases. Annu Surg 1998;227:63-9.

15. Tobe K. Electron microscopy of liver lesions in primary biliary cirrhosis. I. Intrahepatic bile duct oncocytes. Acta Pathol Jpn 1982;32:57-70.

\footnotetext{
STATEMENT OF OWNERSHIP MANAGEMENT AND CIRCULATION (Required by 39 U.S.C. 3685)

1. Publication Title: Modern Pathology

2. Publication no.: 0893-3952. 3. Fling date: 10-01-01. 4. Frequency of issue: Monthly

5. No. of issues published annually: $12 ; 6$. Annual subscription price: $\$ 280.00$.

7. Complete malling address of known office of publication: Lippincott Williams \& Wilkins, 16522 Hunters Green Parkway, Hagerstown, MD 21740-2116. 8. Complete mailing address of the headquarters of general business offices of the publisher: 530 Walnut Street, Philadelphia, PA 19106

9. Full names and complete mailing address of publisher, editor and managing editor: Publisher: Lippincott Williams \& Wilkins 530 Walnut Street, Philadelphia, PA 19106; Editor: John N. Eble, M.D. M. B.A., Pathology (113 Roudebush VAMC), 1481 W. $10^{\text {th }} \mathrm{St}$. Indianapolis, IN 46202-2884. Managing Editor: Brenda M. Randall, Van Nuys Medical Science Building A-128, Indiana University School of Medicine, 635 Barnhill Drive, Indianapolis, IN 46202-5120. 10. Owner: United States and Canadian Academy of Pathology, Fred Silva, M.D., 3643 Walton Way Extension, Augusta, GA 30909.

11. Known bondholders mortgagees, and other security holders owning or holding $1 \%$ or more of total amount of bonds, mortgages or other securities: None.

12. Purpose, function, and nonprofit status: Has not changed during preceding 12 months.

13. Publication Name: Modern Pathology.

14. Issue Date for circulation data: Volume 14, Issue 9

15. Extent and nature of circulation: Average number of copies each issue during preceding 12 months: (a) Total No. copies (Net Press Run) 7,150. (b) Paid and/or requested circulation; (1) Paid/Requested Outside-County Mail Subscriptions Stated on Form 3541 (Include advertiser's proof and exchange copies) 5.037; (2) Paid In-County Subscriptions Stated on (Include advertiser's proof and exchange copies), N/A; (3) Sales Through Dealers and Carriers, Street Vendors, Counter Sales, and Other NonUSPS Paid Distribution, 1,$285 ;$ (4) Other Classes Mailed Through the USPS, N/A. (c) Total Paid and/or Requested Circulation (Sum of $15 \mathrm{~b} .(1),(2),(3)$, and (4)), 6,369. (d) Free Distribution by Mail (Samples, complimentary, and other free). (1) OutsideCounty as Stated on Form 3541, 70; (2) In-county as Stated on Form 3541, N/A: (3) Other Classes Mailed Through the USPS, N/A (e) Free distribution outside the mail (carriers or other means) 99. (f) Total free distribution (sum of 15d and 15e), 169. (g) Total distribution (Sum of $15 \mathrm{c}$ and $15 f$ ) 6,538. (h) Copies not distributed, 612. (i) Total (sum of $15 \mathrm{~g}$ and $\mathrm{h}$ ), 7,150 . (j) Percent Paid and/or Requested Circulation (15c divided by $15 \mathrm{~g}$ times 100 ), $97.42 \%$. No. copies of single issue published nearest to filing date: (a) Total no. copies (Net Press Run), 7,500. (b) Paid and/or requested circulation; (1) Paid/Requested Outside-country mail subscriptions stated on form 3541. (Include advertiser's proof and exchange copies) 5,066; (2) Paid in-county subscriptions (include advertiser's proof and exchange copies. N/A' (3) Sales through dealers and carriers street vendors, counter sales, and other non-USPS Paid Distribution, 1,302 (4) Other classes mailed through the USPS, N/A. (c) Total paid and/or requested circulation (sum of $15 \mathrm{~b},(1),(2),(3)$, and (4)), 6,369 (d) Free distribution by mail (samples, complimentary, and other free copies) free). (1) Outside-County as Stated on Form 3541, 51;(2) In-county as stated on Form 3541,N/A;(3) Other Classes Mailed through the USPS,N/A (e) Free distribution outside the mail (carriers or other means), 53. (f) Total free distribution (sum of 15d and $15 \mathrm{e}$ ) 104. (g) Total distribution (Sum of $15 \mathrm{c}$ and 15f) 6.473. (h) Copies not distributed: 1,027. (i) Total (sum of 15g and h), 7500 (i) Percent Paid and/or Requested Circulation (15c divided by $15 \mathrm{~g}$ times 100 ), $98.39 \%$.

16. This Statement of Ownership will be printed in volume 14 issue 12 of this publication.

17. I certify that the statements made by me above are correct and complete.
} 